\title{
Cerebellar norepinephrine modulates learning of delay classical eyeblink conditioning: Evidence for post-synaptic signaling via PKA
}

\author{
M. Claire Cartford, ${ }^{2,3,5}$ Amy Samec, ${ }^{2,3}$ Mathew Fister, ${ }^{2,3}$ and Paula C. Bickford ${ }^{1,2,3,4,5,6}$ \\ ${ }^{1}$ James A. Haley Veterans Administration Hospital, Tampa, Florida 33612, USA; ${ }^{2}$ Center of Excellence for Aging and Brain Repair, \\ ${ }^{3}$ Department of Neurosurgery, ${ }^{4}$ Department of Pharmacology, and ${ }^{5}$ Neuroscience Program, University of South Florida College of \\ Medicine, Tampa, Florida 33612, USA
}

\begin{abstract}
The neurotransmitter norepinephrine (NE) has been shown to modulate cerebellar-dependent learning and memory. Lesions of the nucleus locus coeruleus or systemic blockade of noradrenergic receptors has been shown to delay the acquisition of several cerebellar-dependent learning tasks To date, no studies have shown a direct involvement of cerebellar noradrenergic activity nor localized the post-synaptic response to cerebellar $\beta$-noradrenergic receptor signaling. Using ipsilateral, localized infusions into cerebellar lobule HVI and interpositus (IP), we have established that blocking $\beta$-noradrenergic receptors with propranolol significantly impairs acquisition of conditioned responses. Furthermore, interrupting activation of cAMP-dependent PKA in the cerebellum using Rp-cAMPS completely prevents acquisition. However, neither blocking $\beta$-adrenergic receptors nor blocking PKA activation significantly interferes with performance of established conditioned responses when administered after the learned response is formed.
\end{abstract}

The neurotransmitter norepinephrine (NE) is strongly implicated in cerebellar-dependent learning and memory in adaptation to a patterned rod runway task (Watson and McElligott 1983; Bickford 1995), in adaptation of the vestibulo-ocular reflex gain (VOR) (Pompeiano et al. 1991), and in cerebellar-dependent delay classical eyelid conditioning (Gould 1998; McCormick and Thompson 1982; Winsky and Harvey 1992; Cartford et al. 2002). The delay form of classical eyelid conditioning is a valuable model for studying NE because the functional anatomy is so well characterized and localization of learning in the cerebellum is strongly supported by the literature. Neurons within cerebellar lobule HVI and the interpositus nucleus (IP) in rabbits and rats show conditioning-related activity (Berthier and Moore 1986; Gould and Steinmetz 1994; Rogers et al. 2001). Classical conditioning of the eyelid response is disrupted by lesions of cerebellar lobule HVI (Yeo et al. 1985; Steinmetz and Sengelaub 1992; Nordholm et al. 1993; Perrett et al. 1993) and is abolished by lesions of cerebellar IP (Clark et al. 1992, 1997; Krupa et al. 1993; Clark and Lavond 1996; Rogers et al. 2001). However, Purkinje cell degeneration mutant (pcd) mice acquire the eyelid response (Chen et al. 1996), and both pcd mice as well as the jaundiced Gunn rat (also a mutant with loss of Purkinje cells) have normal to elevated levels of NE innervation and functional activity in cerebellar cortex and deep nuclei after degeneration of the Purkinje cell layer (Ghetti 1981; Kostrozewa and Harston 1986; Onozuka et al. 1990).

Norepinephrine is known to modulate the action of other neurotransmitters in both the cerebellar cortex and the deep nuclei (Gould et al. 1997) and can amplify afferent inputs to cerebellar Purkinje neurons. This effect is mediated through the $\beta$-noradrenergic receptor (Yeh and Woodward 1983; Woodward et al. 1991). Noradrenergic receptor activation signals a Gprotein-coupled signal transduction cascade in which adenyl cyclase (AC), cyclic-adenosine-monophosphate (cAMP), and pro-

\section{${ }^{6}$ Corresponding author.}

E-mail pbickfor@hsc.usf.edu; fax (813) 974-3078.

Article published online ahead of print. Article and publication date are at http://www.learnmem.org/cgi/doi/10.1101//m.83104. tein kinase A (PKA) are activated and lead to the downstream phosphorylation of multiple substrates including cAMPresponsive element binding protein (CREB). Outside of the cerebellum, cAMP, PKA, and phosphorylated CREB (pCREB) have been implicated in the establishment of synaptic changes necessary for both short-term and long-term memory formation (Taylor et al. 1999; Muller 2000; Vianna et al. 2000; Baldwin et al. 2002; Shobe 2002), and studies in long-term potentiation (LTP) and long-term depression (LTD) support these behavioral findings (Huang et al. 1994; Huang and Kandel 1996; Nayak et al. 1998; Rotenberg et al. 2000). In eyelid conditioning, in particular, Chen and Steinmetz (2000) have shown that localized blocking of a range of kinase activity disrupts acquisition but not retention of conditioning in rabbits. Genetic expression in cerebellum related to eyelid conditioning has not been studied, but there is accumulating evidence for gene expression relative to learning in hippocampus (Donahue et al. 2002) and that blocking genetic expression in cerebellum prevents acquisition of conditioned responses (Gomi et al. 1999). Our hypothesis is that the activity of $\mathrm{NE}$ at the $\beta$-noradrenergic receptors in cerebellum facilitates learning. Finally, we hypothesize that NE signaling mechanisms contribute to learning through activation of PKA, and therefore blocking the activation of PKA will result in learning deficits.

\section{Results}

\section{Learning: Measures of percent conditioned responses $(\% \mathrm{CRs})$}

In order to determine if local administration of propranolol would alter learning of the conditioned responses, rats were treated with propranolol $(100 \mu \mathrm{M} ; 1 \mu \mathrm{L} / 2 \mathrm{~min} ; n=12)$ immediately prior to daily training. Propranolol treatment resulted in significantly decreased \%CRs compared to controls $(1 \mu \mathrm{L} / 2 \mathrm{~min}$; $\left.n=13 ; F_{(25,90.1)}=5.18 ; p<0.008\right)$ (Fig. 1$)$. The propranololtreated animals showed a significant increase in percent conditioned responses from day 1 to day $6(t=-2.414 ; p<0.03)$, sug- 


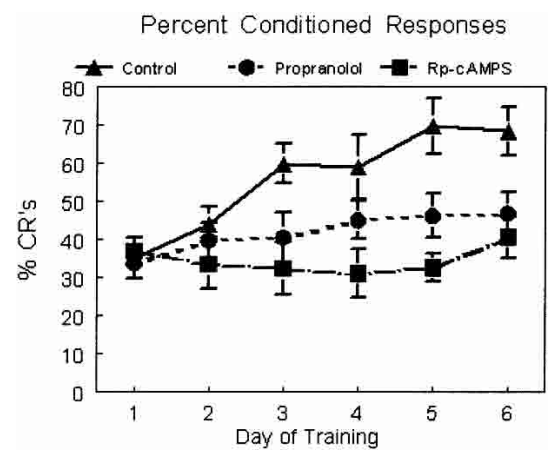

Figure 1. Percent conditioned responses for control (triangles, solid line; $n=13$ ), propranolol (circles, dashed line; $100 \mu \mathrm{M} ; n=12$ ), and Rp-CAMPS (squares, uneven dashed line; $80 \mathrm{nM} ; n=5$ ). Paired trials were presented in daily sessions of 50 trials for $6 \mathrm{~d}$. Drugs were infused $5 \mathrm{~min}$ prior to training. Control rats showed a progressive increase in percent CRs over days and were significantly different from the other two groups (statistics in the body of the text). The propranolol group also showed significant improvement over days of training but did not reach the same performance level as control rats. The Rp-cAMPS group did not show improvement over days of training.

gesting there was some learning in this group even though it was slower than the control group.

To test if potential downstream signal transduction targets of $\beta$-adrenergic receptor stimulation are involved in the acquisition of conditioned responses, we infused the PKA antagonist Rp-cAMPS just prior to training. Treatment with Rp-cAMPS (80 $\mathrm{nM} ; 1 \mu \mathrm{L} / 2 \min ; n=5)$ also resulted in significantly decreased $\%$ CRs compared to controls $\left(n=13 ; F_{(18,90.1)}=10.38 ; p<0.0001\right)$ (Fig. 1). In a comparison of day 1 learning to day 6 learning in this group, there was no significant increase in percent conditioned responses $(t=-1.163$, ns). There was no difference between the two treatment groups (Rp-cAMPS vs. propranolol, $\left.F_{(17,90.1)}=2.36, \mathrm{~ns}\right)$.

\section{Performance: Measures of onset latency, peak latency, and amplitude}

Within the animal groups treatment with Rp-cAMPS or propranolol did not significantly alter the latency to onset of the CR when compared to controls $\left(F_{(18,89.4)}=1.73\right.$, ns; and $F_{(25,89.4)}=2.61$, ns; respectively) (Fig. 2A). The latency to the peak of the conditioned response was significantly earlier in RpcAMPS-infused animals on days 1 and 2, but was not different on subsequent days of training. The animals treated with Rp-cAMPS were significantly different from controls and animals treated with propranolol $\left(F_{(18,89.4)}=6.33 ; p<0.01\right.$; with pairwise comparisons by day; $F_{(17,89.4)}=3.89 ; p<0.05$; respectively) (Fig. $2 \mathrm{~B}$ ). The animals treated with Rp-cAMPS had significantly lower amplitudes of the conditioned response compared to controls on days 2 through 6 , but propranolol-treated animals were not different from controls on this measure $\left(F_{(18,89.9)}=3.12 ; p<0.05\right.$; with pairwise comparisons by day; $F_{(25,89.9)}=2.65$, ns; respectively) (Fig. 2, middle). The data were analyzed for the presence of $\alpha$ responses (defined as a response within the first $70 \mathrm{msec}$ ); there were no significant differences between groups for this measure.

Onset, peak, and amplitude measures were also evaluated in the tone-alone trials. No significant differences were observed between groups over days of training for either time of onset of the response $\left(F_{(2,10)}=1.13 ; p=0.35\right.$; repeated measures ANOVA) or for the time to peak response $\left(F_{(2,20)}=0.54 ; p=0.85\right.$; repeated measures ANOVA). Analysis of the amplitude data for tone alone trials revealed a significant difference between groups across days of training (repeated measures ANOVA; $F_{(2,20)}=2.165 ; p<0.05$ ).

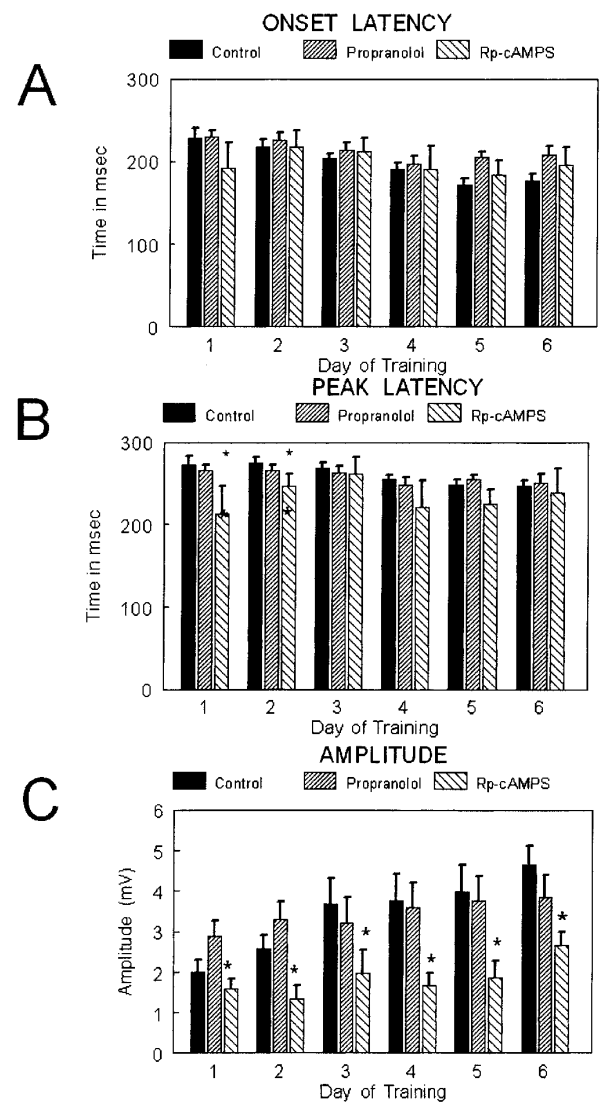

Figure 2. Bar graphs showing $(A)$ onset latency, $(B)$ peak latency, and (C) amplitude of the conditioned responses over days of training for the three groups: control (solid bars; $n=13$ ), propranolol (upward slashed; $n=12$ ), and Rp-cAMPS (downward slashed; $n=5$ ). The statistical comparisons are presented in the text. No differences were observed between groups for onset latency. Peak latency was shorter for the Rp-cAMPS group on days 1 and 2. Amplitude of the CR was lower for the Rp-CAMPS group across all days of training.

Post hoc analysis for individual days revealed differences between the propranolol and Rp-cAMPS group on day 1 (Fisher's PLSD: $\left.F_{(2,23)}=4.28 ; p<0.05\right)$ and control and propranolol on day 3 (Fisher's PLSD: $\left.F_{(2,24)}=3.55 ; p<0.05\right)$ (Fig. $3 C$ ).

To test for drug effects that might skew performance of the behavioral response or interfere with retrieval of memory, an additional group of animals $(n=9)$ received regular paired training for six consecutive days without daily infusions. On day 7 and day 8 the animals were divided into three groups ( $n=3$ per group) and given infusions at doses used above. Group 1 received an infusion of Rp-cAMPS prior to conditioning each day, group 2 received an infusion of propranolol prior to conditioning each day and group 3 received an infusion of the vehicle prior to conditioning each day (Fig. 4). There were no significant differences between these groups in learning, although the number of rats per group is low and this must be taken into consideration. In behavioral performance there was no Rp-cAMPS or propranolol effect on CR peak or amplitude $\left(F_{(2,814.3)}=0.686\right.$, ns; and $F_{(2,27.38)}=3.165$, ns; respectively). The subjects that received infusions of Rp-cAMPS and propranolol had later onset of CRs on day 8 only $\left(F_{(2,1752.33)}=9.599, p<0.01\right.$; Fisher's PLSD significant for day 8 only).

\section{Discussion}

Using ipsilateral, localized infusions into cerebellar HVI and IP, we have established that blocking $\beta$-noradrenergic receptors sig- 


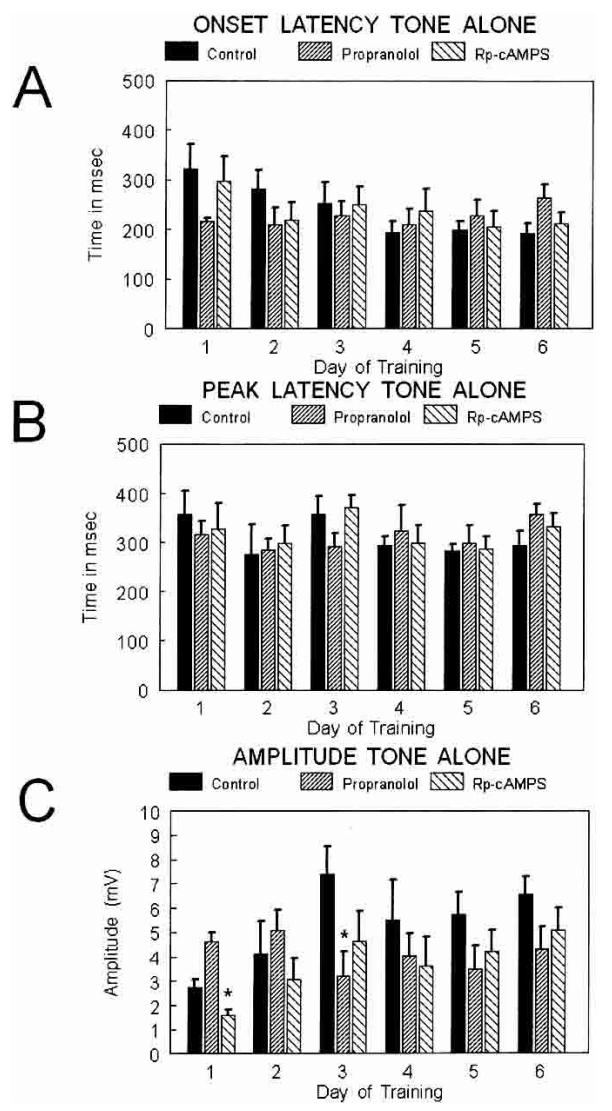

Figure 3. Bar graphs showing $(A)$ onset latency, $(B)$ peak latency, and (C) amplitude of the conditioned responses for the tone alone trials over days of training for the three groups: control (solid bars; $n=6$ ), propranolol (upward slashed; $n=12$ ), and Rp-cAMPS (downward slashed; $n=5$ ). The statistical comparisons are presented in the text. No differences were observed between groups for onset latency or peak latency. The amplitude was higher for propranolol rats on day 1 compared with the Rp-CAMPS group, and on day 3 the amplitude for propranolol was significantly lower than control.

nificantly impairs acquisition of conditioned responses, and interrupting activation of cAMP-dependent PKA in the cerebellum completely prevents acquisition. However, neither blocking $\beta$-adrenergic receptors nor blocking PKA activation significantly interferes with performance of established conditioned responses when administered after the learned response is formed.

The results support our prior findings that the $\beta$-noradrenergic receptor blocker propranolol, when systemically administered, disrupts learning in delay classical eyeblink conditioning (Gould 1998; Cartford et al. 2002). We now have significant data indicating that localized application of this agent in cerebellar lobule HVI and IP significantly affects learning, but does not disrupt performance of the learned response. This result supports the contention that the activity of NE in the cerebellum is important for adaptation and lasting changes related to memory formation. Earlier evidence for this was established using cerebellar NE depletion in a rod-running motor learning paradigm, (Watson and McElligott 1984) as well as with blocking $\beta$-noradrenergic receptors during adaptation of the VOR (Pompeiano et al. 1991). Our subjects did show some indication of learning. Their percent CR scores on day 6 were significantly higher than on day 1 . It is possible that with additional training trials these animals would have reached the same level of conditioning as the control group. On the other hand, the propranolol and RpcAMPS groups were not significantly different from each other

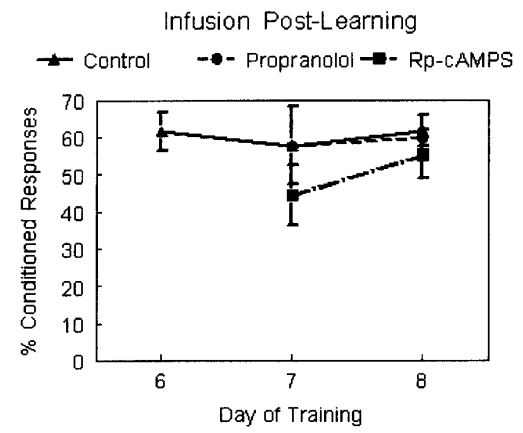

Figure 4. Graph showing percent CRs for days 6 through 8 of training. Infusions were not performed for the initial training period (data not shown); infusions were initiated on day 7 of training. Neither propranolol (circles, dashed line; $n=3$ ) nor Rp-cAMPS (squares, uneven dashed line; $n=3$ ) were different from control (triangles, solid lines; $n=3$ ) demonstrating that neither drug affected performance of the learned response.

on acquisition training but were both different from the control animals. In previous experiments with propranolol (Heron et al. 1996), animals trained on a motor learning task showed significant impairment of learning, but with additional training were able to reach levels of learning that corresponded to control groups. The effect we see in our current results may be related to the dose of propranolol, or to the duration of training. A future experiment is needed to determine whether these animals would achieve conditioned responding levels equal to those of controls given more training trials, and to determine whether there is any actual difference between treatment with propranolol or with Rp-cAMPS in this regard.

The results indicate that blocking activation of cAMPdependent PKA also disrupts learning of the delay form of the eyeblink conditioning task and that there was no improvement over days of training in the rats treated with Rp-cAMPS. There is a growing body of literature implicating PKA in learning and memory formation, although most of this work has been performed in brain regions other than the cerebellum (Vianna et al. 2000). For example, PKA activity is increased in the hippocampus immediately following training on a one-trial active avoidance task; PKA activity then declines and is again increased at $3 \mathrm{~h}$ following training (Vianna et al. 2000). Likewise, inhibition of PKA with Rp-cAMPS inhibits long-term memory formation of the one-trial avoidance when administered either at the time of training, or 3-6 $\mathrm{h}$ following training (Vianna et al. 2000). The later phase of this activation of PKA is related in time to formation of late-phase LTP, and these investigators have also demonstrated that long-term memory formation requires protein synthesis as anisomycin will interfere with long-term memory formation in this task (Vianna et al. 2001). Eyelid conditioning is dependent on the expression of a variety of protein kinases (Gomi et al. 1999; Chen and Steinmetz 2000; Sassa et al. 2000) and blocking gene transcription in IP blocks eyelid conditioning in rabbits (Gomi et al. 1999), showing that initiation of protein synthesis is likely to be important for eyelid conditioning. As we have demonstrated here that PKA is important for eyelid conditioning, one likely candidate for activation of transcription during eyelid conditioning is phosphorylation of CREB by activated PKA. However, CREB can be phosphorylated by other mechanisms such as $\mathrm{Ca}^{2+}$ and $\mathrm{PKC}$, both of which have been implicated in cerebellar LTD; further experiments will be needed to test this hypothesis.

We observed a difference between NE receptor blockade and blocking PKA activation on the extent of interruption of acquiring the CR. One explanation for this might be that $\beta$-noradrenergic receptors are not the only mechanism in cerebellum 
whereby PKA is activated. When $\beta$-noradrenergic receptors are blocked there may not be a large enough change in PKA signaling to have the profound effects seen when PKA activation itself is blocked with Rp-cAMPS. We observed that Rp-cAMPS infusions resulted in decreased amplitude and altered timing of conditioned responses. This was true during acquisition only and only on select days of training. In animals already trained without infusions, Rp-cAMPS infusions resulted in only mild changes in onset latency of conditioned responses. These two results indicate that Rp-cAMPS effects are wedded to mechanisms associated with learning in the cerebellum. We know from electrophysiological studies that NE modulates the inhibitory activity of GABA in both the cerebellar cortex and deep nuclei (Gould and Bickford 1997). It has been shown that $\mathrm{GABA}_{\mathrm{A}}$ activity in cerebellar cortex and deep nuclei may contain the "memory" for different aspects of the learned behavior (Bao et al. 2002). For instance, timing of the conditioned response is mediated by cerebellar cortex (Garcia and Mauk 1998). Our results showing changes in both timing and amplitude would indicate that blocking PKA activity in both cerebellar cortex and deep nuclei results in compound performance deficits related specifically to the learned behavior. The mixed effects seen in our experiment, including timing and amplitude changes, could indicate effects of PKA blockade at both levels of cerebellum, whereas in animals already trained, blocking PKA activation has no effect on cerebellar output of the learned response. This would confirm our belief that PKA activation is necessary for learning rather than for performance of the learned behavior. If a primary or secondary memory trace is forming during acquisition that includes the size, shape, and timing of the learned output, then the mechanisms necessary to stabilize this adaptation and output must be in play during acquisition. Using the knowledge we have gained regarding the timing of $\mathrm{NE}$ activation in cerebellum, we will be able examine the timing of NE receptor and PKA blockade relative to learning and memory formation.

In summary, we have shown that blocking either $\beta$-noradrenergic receptors, or one of the downstream targets of $\beta$-adrenergic receptors, cAMP-dependent PKA, results in significant disruption of acquisition of CRs. Future questions to be considered include whether the effects of NE blockade on eyelid conditioning are a result of disruption of GABAergic signaling in cerebellar cortex and deep nucleus, and whether NE activation of PKA is necessary or sufficient to disrupt genetic transcription required for laying down long-term memories.

\section{Materials and Methods}

\section{Animals}

Male, F344 rats were housed in the James A. Haley Veterans Hospital animal colony under the supervision of the animal care staff, the institutional animal care and use committee, and the veterinarians of the University of South Florida School of Medicine and the Veterans Hospital. Animals were housed in pairs before surgery and singly after surgery and were kept on a 12-h light/dark schedule with ad lib access to food and water.

\section{Surgery}

The subjects were anesthetized for surgery with xylazine $(10 \mathrm{mg} /$ $\mathrm{kg}$ ) and ketamine $(70 \mathrm{mg} / \mathrm{kg})$. The cranium was exposed and three stainless steel skull screws were placed in the bone to anchor the headstage. Two EMG wires (consisting of stainless steel wire 0.003 bare with 0.0045 Teflon; coatAM Systems) were placed under the skin of the upper eyelid using a suture needle protruding at the distal edge of the eyelid. The distal end of the wire was stripped of the Teflon coating to a point $\sim 3 \mathrm{~mm}$ under the skin of the eyelid. The two wires were placed at least $6 \mathrm{~mm}$ apart on the eyelid. A third wire was fully stripped and fixed to one of the skull screws to serve as a ground wire. Gold pins were crimped to these wires and were plugged into an ITT/Cannon connector strip (PEI Genesis). A guide cannula consisting of 27-gauge stainless steel hypodermic tubing (Small Parts, Inc.) cut to a total length of 1.5 $\mathrm{cm}$ was implanted into cerebellum of each subject at stereotaxic coordinates AP $-10.8, \mathrm{ML}+2.7$ and DV -4.5 (Paxinos and Watson 1986). The headstage and guide cannula were fixed to the head of the animal using dental acrylic. On day 8 following surgery the animals were handled for $15 \mathrm{~min}$ and habituated to the training chamber for $0.5 \mathrm{~h}$. On the day following habituation training began.

\section{Data collection}

The recording chamber was a melamine-coated box $(22 \times 22 \times 45$ $\mathrm{cm}$ ) with a plastic door that allowed the rat to be observed from the front. This box was set inside a larger sound-attenuating chamber (both chambers were constructed in our laboratory). The larger box was outfitted with a ventilation fan and a speaker for delivery of the tone. The airpuff pressure was controlled with a Fisher Scientific two-stage regulator. Headstages coupled to a cable and commutator (developed and constructed by Eclectic Engineering Studio) in the training chamber, thus allowing eyelid EMG signals to be analyzed. The EMG signal was directed through an FET (field effect transistor) to a DAM 50 differential amplifier (low filter 300, high filter 3K; World Precision Instruments) and amplified $10 \times$. From the DAM50 the signal passed to an A-M Systems differential amplifier and was filtered between 300 and $5000 \mathrm{~Hz}$ with a gain of 100 . The EMG signal was rectified and integrated with electronics constructed for our laboratory (Levin and Associates) and was monitored using a digital storage oscilloscope. The tone was a $3 \mathrm{kHz}, 85 \mathrm{~dB}$ square wave signal emitted by a Beckman Industrial FG2A Function Generator. The decibel level in the recording chamber was monitored using a GenRad 1982 Precision Sound Level Meter and Analyzer (now IET Labs Inc.). Delivery of the stimuli and collection of EMG data was accomplished using a control box developed by Tracy and Steinmetz (Indiana University Department of Psychology, Bloomington, IN) and Rabcon software (also developed by Steinmetz, Indiana University Department of Psychology, Bloomington, IN). Data collected from the rats were analyzed using a Microsoft Excel Macro developed by Green and Steinmetz (Indiana University Department of Psychology, Bloomington, IN).

Pharmacologic agents infused into cerebellum $(1 \mu \mathrm{L}$ total infusion volume) included $100 \mu \mathrm{M}$ propranolol and $80 \mathrm{nM} \mathrm{Rp}-$ cAMPS (Sigma-Aldrich). Each was dissolved in 0.1 M PBS (pH 7.4), which served as the vehicle control substance. To infuse the drugs we used PE-20 polyethylene tubing connected to a $10-\mu \mathrm{L}$ Hamilton syringe. Infusions were regulated using a syringe pump (Sage Instruments). The rate of infusion was $1 \mu \mathrm{L} / 2 \mathrm{~min}$. Doses for propranolol and RpcAMPS were determined with pilot groups as well as reports by other laboratory studies using these agents for behavioral studies in vivo. Daily infusions were made immediately prior to training. Histological verification of cannula placement was confirmed for each rat before the data were analyzed. Typical placement of the infusion cannula is shown in Figure 5.

\section{Training parameters}

Animals received delay classical conditioning consisting of one session of 50 training trials each day for six consecutive days. The training trials were grouped into five blocks of 10 trials, each block consisting of one tone-alone trial and nine paired trials. Each training trial was $750 \mathrm{msec}$ in length and consisted of a 250-msec baseline period followed by a 400-msec CS period followed by a final $100-\mathrm{msec}$ US period. The tone came on at 250 msec and remained on for $500 \mathrm{msec}$. The airpuff came on at 650 $\mathrm{msec}$ and remained on for $100 \mathrm{msec}$. The tone and airpuff overlapped for $100 \mathrm{msec}$ and then coterminated. Trials were separated by a randomized 10 -to-30 sec intertrial interval. 


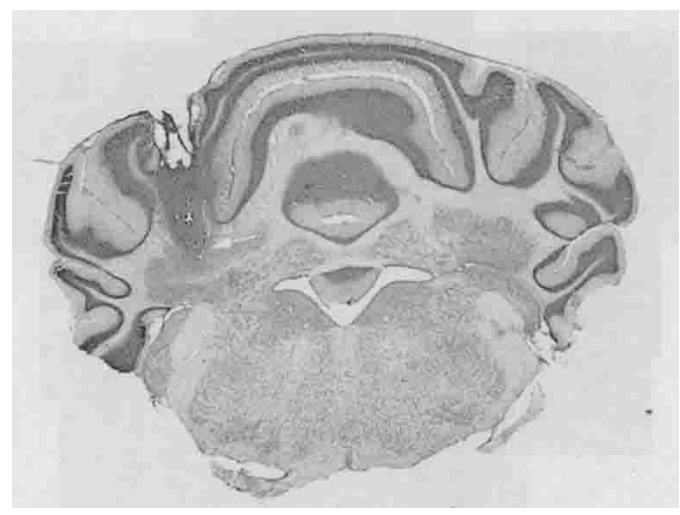

Figure 5. Montage showing a typical cannula placement. The tip of the cannula (indicated by the arrow) was just above the interpositus nucleus, and the area of infusion included the lobus simplex.

\section{Data analysis}

The percent of conditioned responses that animals made in a daily training session was used as a measure of learning. A conditioned response was defined as movement of the eyelid that was significantly greater than baseline (at least 10 standard deviations), and that occurred in the last $330 \mathrm{msec}$ of the CS period and before the US period. A discrimination window of $70 \mathrm{msec}$ following the tone onset was used to avoid having spontaneous blinks to the tone ( $\alpha$ responses) recorded as conditioned responses. Performance of the learned behavior was evaluated by examining the amplitude of the conditioned response, the onset timing of the conditioned response, and the timing of the peak of the conditioned response; only trials in which a CR was observed were analyzed. The experimental conditions were identical across experiments. For analysis purposes groups were compared within an experiment as well as across experiments. A linear mixed-effects modeling approach appropriate for repeated measures data was used to examine four responses as a function of day of training (Laird and Ware 1982). The four responses examined included (1) percent conditioned responses, (2) onset latency of the conditioned response, (3) amplitude of the conditioned response, and (4) timing of the peak of the conditioned response.

\section{Acknowledgments}

This work was supported by NSF grant 0196474, USPHS grant AG04418, and the VAMRS.

\section{References}

Baldwin, A.E., Sadeghian, K., Holahan, M.R., and Kelley, A.E. 2002. Appetitive instrumental learning is impaired by inhibition of cAMP-dependent protein kinase within the nucleus accumbens. Neurobiol. Learn. Mem. 77: 44-62.

Bao, S., Chen, L., Kim, J.J., and Thompson, R.F. 2002. Cerebellar cortical inhibition and classical eyeblink conditioning. Proc. Natl. Acad. Sci. 99: 1592-1597.

Berthier, N.E. and Moore, J.W. 1986. Cerebellar Purkinje cell activity related to the classically conditioned nictitating membrane response. Exp. Brain Res. 63: 341-350.

Bickford, P. 1995. Aging and motor learning: A possible role for norepinephrine in cerebellar plasticity. Rev. Neurosci. 6: 35-46.

Cartford, M.C., Allgeier, C.A., and Bickford, P.C. 2002. The effects of $\beta$-noradrenergic receptor blockade on acquisition of eyeblink conditioning in 3-month-old F344 rats. Neurobiol. Learn. Mem. 78: $246-257$.

Chen, G. and Steinmetz, J.E. 2000. Microinfusion of protein kinase inhibitor $\mathrm{H} 7$ into the cerebellum impairs the acquisition but not the retention of classical eyeblink conditioning in rabbits. Brain Res. 856: $193-201$.

Chen, L., Bao, S., Lockard, J.M., Kim, J.J., and Thompson, R.F. 1996. Impaired classical eyeblink conditioning in cerebellar-lesioned and Purkinje cell degeneration (pcd) mutant mice. J. Neurosci. 16: $2829-2838$.
Clark, R.E. and Lavond, D.G. 1996. Neural unit activity in the trigeminal complex with interpositus or red nucleus inactivation during classical eyeblink conditioning. Behav. Neurosci. 110: 13-21.

Clark, R.E., Zhang, A.A., and Lavond, D.G. 1992. Reversible lesions of the cerebellar interpositus nucleus during acquisition and retention of a classically conditioned behavior. Behav. Neurosci. 106: $879-888$.

Clark, R., Gohl, E.B., and Lavond, D.G. 1997. The learning-related activity that develops in the pontine nuclei during classical eyeblink conditioning is dependent on the interpositus nucleus. Learn. Mem. 3: $532-544$.

Donahue, C.P., Jensen, R.V., Ochiishi, T., Eisenstein, I., Zhao, M., Shors, T., and Kosik, K.S. 2002. Transcriptional profiling reveals regulated genes in the hippocampus during memory formation. Hippocampus 12: 821-833.

Garcia, K.S. and Mauk, M.D. 1998. Pharmacological analysis of cerebellar contributions to the timing and expression of conditioned eyelid responses. Neuropharmacology 37: 471-480.

Ghetti, B. 1981. Purkinje cell loss and the noradrenergic system in the cerebellum of pcd mutant mice. Brain Res. Bull. 7: 711-714.

Gomi, H., Sun, W., Finch, C.E., Itohara, S., Yoshimi, K., and Thompson, R.F. 1999. Learning induces a CDC2-related protein kinase, KKIAMRE. J. Neurosci. 19: 9530-9537.

Gould, T.J. 1998. $\beta$-Adrenergic involvement in acquisition vs. extinction of a classically conditioned eye blink response in rabbits. Brain Res. 780: $174-177$.

Gould, T.J. and Bickford, P.C. 1997. Age-related deficits in the cerebellar $\beta$ adrenergic signal transduction cascade in Fischer 344 rats. $J$. Pharmacol. Exp. Therapeutics 281: 965-971.

Gould, T.J. and Steinmetz, J.E. 1994. Multiple-unit activity from rabbit cerebellar cortex and interpositus nucleus during classical discrimination/reversal eyelid conditioning. Brain Res. 652: 98-106.

Gould, T.J., Adams, C.E., and Bickford, P.C. 1997. $\beta$-Adrenergic modulation of gabaergic inhibition in the deep cerebellar nuclei of F344 rats. Neuropharmacology 36: 75-81.

Heron, C., Gould, T.J., and Bickford, P. 1996. Acquisition of a runway motor learning task is impaired by a $\beta$ adrenergic antagonist in F344 rats. Behav. Brain Res. 78: 235-241.

Huang, Y.Y. and Kandel, E.R. 1996. Modulation of both the early and the late phase of mossy fiber LTP by the activation of $\beta$-adrenergic receptors. Neuron 16: 611-617.

Huang, Y.Y., Li, X.C., and Kandel, E.R. 1994. cAMP contributes to mossy fiber LTP by initiating both a covalently mediated early phase and macromolecular synthesis dependent late-phase. Cell 79: 69-79.

Kostrozewa, R.M. and Harston, C.T. 1986. Altered histofluorescent pattern of noradrenergic innervation of the cerebellum of the mutant mouse Purkinje cell degeneration. Neuroscience 18: 809-815.

Krupa, D.J., Thompson, J.K., and Thompson, R.F. 1993. Localization of a memory trace in the mammalian brain. Science 260: 989-991.

Laird, N.M. and Ware, J.H. 1982. Random-effects models for longitudinal data. Biometrics 38: 963-974.

McCormick, D.A. and Thompson, R.F. 1982. Locus coeruleus lesions and resistance to extinction of a classically conditioned response: Involvement of the neocortex and hippocampus. Brain Res. 245: 239-249.

Muller, U. 2000. Prolonged activation of cAMP-dependent protein kinase during conditioning induces long-term memory in honeybees. Neuron 27: 159-168.

Nayak, A., Zastrow, D.J., Lockteig, R., Zahniser, N.R., and Browning, M.D. 1998. Maintenance of the late-phase of LTP is accompanied by PKA-dependent increase in AMPA receptor synthesis. Nature 394: 680-683.

Nordholm, A.F., Thompson, J.K., Dersarkissian, C., and Thompson, R.F. 1993. Lidocaine infusion in a critical region of cerebellum completely prevents learning of the conditioned eyeblink response. Behav. Neurosci. 107: 882-886.

Onozuka, M., Kubo, K., Deura, S., Karasawa, N., and Nagatsu, I. 1990. Modification of noradrenergic innervation in the cerebellum of mutant rats with Purkinje cell degenration (jaundiced Gunn rats). Neuroscience Res. 9: 140-147.

Paxinos, G. and Watson, C. 1986. The rat brain in stereotaxic coordinates. Academic Press, San Diego, CA.

Perrett, S.P., Ruiz, B.P., and Mauk, M.D. 1993. Cerebellar cortex lesions disrupt learning-dependent timing of conditioned eyeblink responses. J. Neurosci. 13: 1708-1718.

Pompeiano, O., Van Neerven, J., Collewijn, H., and Van der Steen, J. 1991. Changes in VOR adaptation after local injection of $\beta$-noradrenergic agents in the flocculus of rabbits. Acta Otolaryngologica (Stockholm) 111: 176-181.

Rogers, R.F., Britton, G.B., and Steinmetz, J.E. 2001. Learning-related interpositus activity is conserved across species as studied during eyeblink conditioning in the rat. Brain Res. 905: 171-177.

\section{Learning \& Memory}


Rotenberg, A., Abel, T., Hawkins, R.D., Kandel, E.R., and Muller, R.U. 2000. Parallel instabilities of long-term potentiation, place cells, and learning caused by decreased protein kinase A activity. J. Neurosci. 20: $8096-8102$.

Sassa, T., Gomi, H., Sun, W., Ikeda, T., Thompson, R.F., and Itohara, S. 2000. Identification of variants and dual promoters of murine serine/threonine kinase KKIAMRE. J. Neurochem. 74: 1809-1819.

Shobe, J. 2002. The Role of PKA, CaMKII, and PKC in avoidance conditioning: Permissive or instructive? Neurobiol. Learn. Mem. 77: 291-312.

Steinmetz, J.E. and Sengelaub, D.R. 1992. Possible conditioned stimulus pathway for classical eyelid conditioning in rabbits. I. Anatomical evidence for direct projections from the pontine nuclei to the cerebellar interpositus nucleus. Behav. Neural Biol. 57: 103-115.

Taylor, J.R., Birnbaum, S., Ubriani, R., and Arnsten, A.F. 1999. Activation of cAMP-dependent protein kinase A in prefrontal cortex impairs working memory performance. J. Neurosci. 19: RC23.

Vianna, M.R., Izquierdo, L.A., Barros, D.M., Ardenghi, P., Pereira, P., Rodrigues, C., Moletta, B., Medina, J.H., and Izquierdo, I. 2000. Differential role of hippocampal cAMP-dependent protein kinase in short- and long-term memory. Neurochemistry Res. 25: 621-626.

Vianna, M.R., Szapiro, G., McGaugh, J.L., Medina, J.H., and Izquierdo, I. 2001. Retrieval of memory for fear-motivated training initiates extinction requiring protein synthesis in the rat hippocampus. Proc.
Natl. Acad. Sci. 98: 12251-12254.

Watson, M. and McElligott, J.G. 1983. 6-OHDA induced effects upon the acquisition and performance of specific locomotor tasks in rats. Pharmacol. Biochem. Behav. 18: 927-934.

. 1984. Cerebellar norepinephrine depletion and impaired acquisition of specific locomotor tasks in rats. Brain Res. 296: $129-138$.

Winsky, L. and Harvey, J.A. 1992. 6-Hydroxydopamine induced impairment of Pavlovian conditioning in the rabbit. Neurochem. Res. 17: 415-422.

Woodward, D.J., Moises, H.C., Waterhouse, B.D., Yeh, H.H., and Cheun, J.E. 1991. Modulatory actions of norepinephrine on neural circuits. Advan. Exp. Med. Biol. 287: 193-208.

Yeh, H.H. and Woodward, D.J. 1983. $\beta-1$ adrenergic receptors mediate noradrenergic facilitation of Purkinje cell responses to $\gamma$-aminobutyric acid in cerebellum of rat. Neuropharmacology 22: 629-639.

Yeo, C.H., Hardiman, M.J., and Glickstein, M. 1985. Classical conditioning of the nictitating membrane response of the rabbit. II. Lesions of the cerebellar cortex. Exp. Brain Res. 60: 99-113.

Received June 21, 2004; accepted in revised form October 5, 2004. 


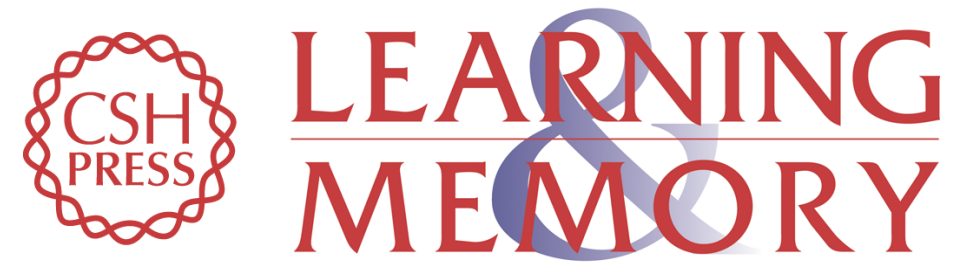

\section{Cerebellar norepinephrine modulates learning of delay classical eyeblink conditioning: Evidence for post-synaptic signaling via PKA}

M. Claire Cartford, Amy Samec, Mathew Fister, et al.

Learn. Mem. 2004, 11:

Access the most recent version at doi:10.1101//m.83104

References This article cites 43 articles, 9 of which can be accessed free at: http://learnmem.cshlp.org/content/11/6/732.full.html\#ref-list-1

License

Email Alerting

Receive free email alerts when new articles cite this article - sign up in the box at the Service top right corner of the article or click here. 